\title{
Preoperative evaluation and surgical management of infants and toddlers with drug-resistant epilepsy
}

\author{
*Jonathan Pindrik, MD, ${ }^{1,2}$ Nguyen Hoang, MD, ${ }^{2}$ Luke Smith, MD, ${ }^{2}$ Mark Halverson, MD, ${ }^{3}$ \\ Mary Wojnaroski, PhD, ${ }^{4}$ Kelly McNally, PhD, ABPP, ${ }^{4}$ Satyanarayana Gedela, MD, MRCP, ${ }^{5}$ and \\ Adam P. Ostendorf, MD ${ }^{5}$
}

${ }^{1}$ Division of Pediatric Neurosurgery, Department of Neurosurgery, ${ }^{3}$ Division of Pediatric Neuroradiology, Department of Radiology, and ${ }^{4}$ Section of Pediatric Psychology and Neuropsychology, Department of Pediatrics, Nationwide Children's Hospital; ${ }^{2}$ Department of Neurological Surgery, The Ohio State University College of Medicine; and ${ }^{5}$ Division of Child Neurology, Department of Pediatrics, Nationwide Children's Hospital and The Ohio State University College of Medicine, Columbus, Ohio

\begin{abstract}
OBJECTIVE Despite perioperative risks, epilepsy surgery represents a legitimate curative or palliative treatment approach for children with drug-resistant epilepsy (DRE). Several factors characterizing infants and toddlers with DRE create unique challenges regarding optimal evaluation and management. Epilepsy surgery within children $<3$ years of age has received moderate attention in the literature, including mainly case series and retrospective studies. This article presents a systematic literature review and explores multidisciplinary considerations for the preoperative evaluation and surgical management of infants and toddlers with DRE.
\end{abstract}

METHODS The study team conducted a systematic literature review based on Preferred Reporting Items for Systematic Reviews and Meta-Analyses (PRISMA) guidelines, targeting studies that investigated children < 3 years of age undergoing surgical treatment of DRE. Using the PubMed database, investigators selected peer-reviewed articles that reported seizure outcomes with or without developmental outcomes and/or perioperative complications. Studies were eliminated based on the following exclusion criteria: sample size < 5 patients; and inclusion of patients $>3$ years of age, when demographic and outcomes data could not be separated from the cohort of patients $<3$ years of age.

RESULTS The study team identified 20 studies published between January 1990 and May 2017 that satisfied eligibility criteria. All selected studies represented retrospective reviews, observational studies, and uncontrolled case series. The compiled group of studies incorporated 465 patients who underwent resective or disconnective surgery (18 studies, 444 patients) or vagus nerve stimulator insertion ( 2 studies, 21 patients). Patient age at surgery ranged between 28 days and 36 months, with a mean of 16.8 months (1.4 years).

DISCUSSION The study team provided a detailed summary of the literature review, focusing on the etiologies, preoperative evaluation, surgical treatments, seizure and developmental outcomes, and potential for functional recovery of infants and toddlers with DRE. Additionally, the authors discussed special considerations in this vulnerable age group from the perspective of multiple disciplines.

CONCLUSIONS While presenting notable challenges, pediatric epilepsy surgery within infants and toddlers (children < 3 years of age) offers significant opportunities for improved seizure frequency, neuro-cognitive development, and quality of life. Successful evaluation and treatment of young children with DRE requires special consideration of multiple aspects related to neurological and physiological immaturity and surgical morbidity.

https://thejns.org/doi/abs/10.3171/2018.7.FOCUS18220

KEYWORDS drug-resistant epilepsy; epilepsy surgery; infants; toddlers; phase I evaluation; phase II monitoring

\footnotetext{
ABBREVIATIONS DNET = dysembryoplastic neuroepithelial tumor; $\mathrm{DQ}=$ developmental quotient; $\mathrm{DRE}=$ drug-resistant epilepsy; $E C$ og = electrocorticography; $E \mathrm{EG}$ = electroencephalography; ESM = electrical stimulation mapping; ETLE = extratemporal lobe epilepsy; FCD = focal cortical dysplasia; FDG = fluorodeoxyglucose; ICEEG = intracranial electroencephalography; ICP = intracranial pressure; LTME = long-term monitoring electroencephalography; MCD = malformations of cortical development; MEG = magnetoencephalography; PET = positron emission tomography; PRISMA = Preferred Reporting Items for Systematic Reviews and Meta-Analyses; SEEG = stereotactic electroencephalography; SLA = stereotactic laser ablation; SWS = Sturge-Weber syndrome; TSC = tuberous sclerosis complex; VNS = vagus nerve stimulator.

SUBMITTED April 30, 2018. ACCEPTED July 5, 2018.
}

INCLUDE WHEN CITING DOI: 10.3171/2018.7.FOCUS18220.

* J.P. and N.H. contributed equally to this work and share first authorship. 
$\mathrm{D}$ RUG-RESISTANT epilepsy (DRE), defined as inadequate seizure control despite adequate trials of two antiseizure medications, represents a debilitating condition for adults and children. ${ }^{47} \mathrm{~A}$ subset of patients with DRE may achieve seizure control following surgical intervention. While presenting notable challenges, pediatric epilepsy surgery within infants and toddlers (children $<3$ years of age) offers significant opportunities for seizure freedom or reduction, developmental recovery and/or improvement, and enhanced quality of life for both patients and families. ${ }^{24,64,69}$ Cerebral plasticity during infancy and early childhood also offers potential benefits of enhanced functional recovery following surgery. However, young chronological and developmental age create unique challenges regarding presurgical evaluation (phase I monitoring), surgical planning, and decision-making due to increased risks from physiological immaturity and limited blood volume.

Improvements in presurgical evaluation, neuroimaging, neuro-anesthesia, and surgical technique have increased the safety and potential for favorable outcomes in the surgical management of DRE in very young patients. Many articles (mostly case series) have reported clinical outcomes with invasive epilepsy surgery involving children < 3 years of age. In this article, the authors provide a systematic literature review and explore special considerations for the preoperative evaluation and surgical management of infants and toddlers with DRE.

\section{Methods}

A systematic literature review was conducted in accordance with Preferred Reporting Items for Systematic Reviews and Meta-Analyses (PRISMA) guidelines, analyzing data from studies reporting on children $<3$ years of age undergoing surgical treatment of DRE and reported seizure outcomes with or without developmental outcomes and/or perioperative complications. Using the PubMed database, the study team searched for articles published from January 1985 through May 2018 with the following key terms: ("epilepsy surgery," "epilepsy," "resection," "VNS," "vag\$ nerve stimulation," "callosotomy”) AND ("pediatric," "toddlers," "young," "infancy," "infants," "children"). Additional manuscripts were found through reference lists from pertinent articles. Full-text English language studies published in peer-reviewed journals were selected. Studies were excluded based on the following: 1) sample size < 5 patients and 2) inclusion of patients older than 3 years, when demographic and outcomes data could not be separated from the cohort of patients less than 3 years of age. Eligible studies were evaluated critically based on study type and characteristics. From each qualifying study, investigators abstracted the following information: patient demographics, seizure etiology, surgical interventions, histopathology, seizure and developmental outcomes, and perioperative complications.

\section{Results}

The initial search criteria identified 1710 studies from the PubMed database and exploration of reference lists from pertinent studies (Fig. 1). Twenty eligible stud-

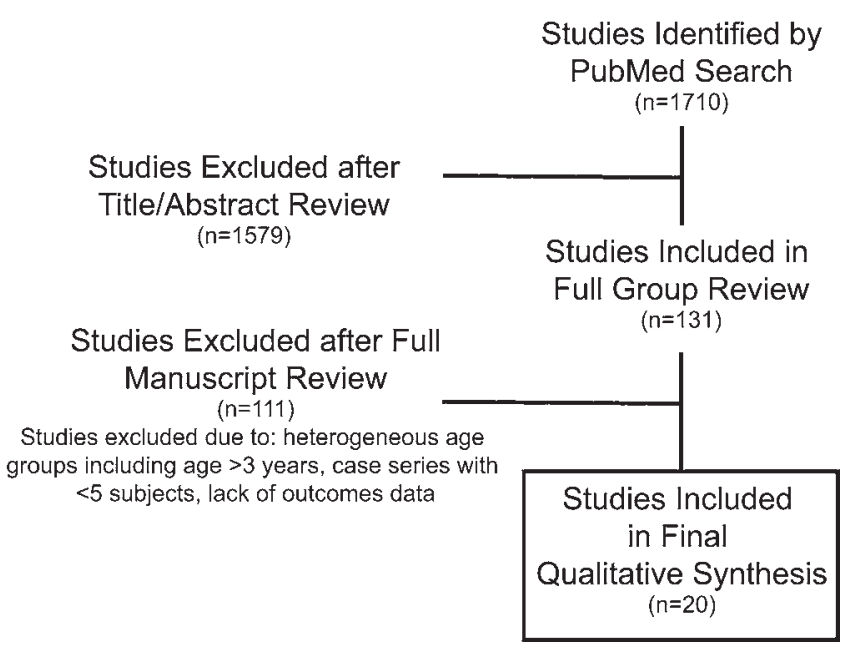

FIG. 1. PRISMA flowchart for study selection. This diagram demonstrates the selection of peer-reviewed studies based on PRISMA guidelines and the study team's inclusion and exclusion criteria.

ies were identified; all were published between January 1990 and May 2017. This systematic search revealed no randomized controlled trials or prospective cohort studies satisfying the criteria for inclusion, as 2 notable studies were eliminated based on the inability to separate data for patients less than 3 years of age. ${ }^{23,55}$ All selected studies represented retrospective reviews, observational studies, and uncontrolled case series, representing low quality of evidence.

Within the 20 included manuscripts, data were available for 465 individuals who underwent resective or disconnective surgery (18 studies, 444 individuals total) or vagus nerve stimulator (VNS) insertion (2 studies, 21 individuals total) (Tables 1 and 2). The studies varied widely regarding number of patients, with a range of 5 to $116 . .^{21,69}$ Among these studies, patient age at surgery ranged between 28 days and 36 months, with a mean of 16.8 months.

\section{Discussion}

\section{Summary of Literature Review}

In contrast to the typical etiologies of DRE in older children and adults, the etiologies of DRE predominating in very young children included hemispheric syndromes such as Sturge-Weber syndrome (SWS), Rasmussen encephalitis, and hemimegalencephaly; malformations of cortical development (MCD) such as focal cortical dysplasia (FCD), polymicrogyria, and heterotopias; vascular malformations or stroke; tuberous sclerosis complex (TSC); neoplasms such as ganglioglioma, dysembryoplastic neuroepithelial tumor (DNET), other low-grade tumors, and malignant tumors; gliosis; and prior infection such as encephalitis (Table 1). ${ }^{30,35,40,44,45,50,51,69,70,73}$ Prevalence estimates of each etiology generally agreed with those reported by Harvey et al. in children younger than 4 years with DRE in an international survey of epilepsy procedures. ${ }^{34}$ Overall, only approximately $1 \%$ of infants and toddlers with DRE (4 of 444) harbored hippocampal sclerosis.

The distinct etiologies of DRE in children below 3 


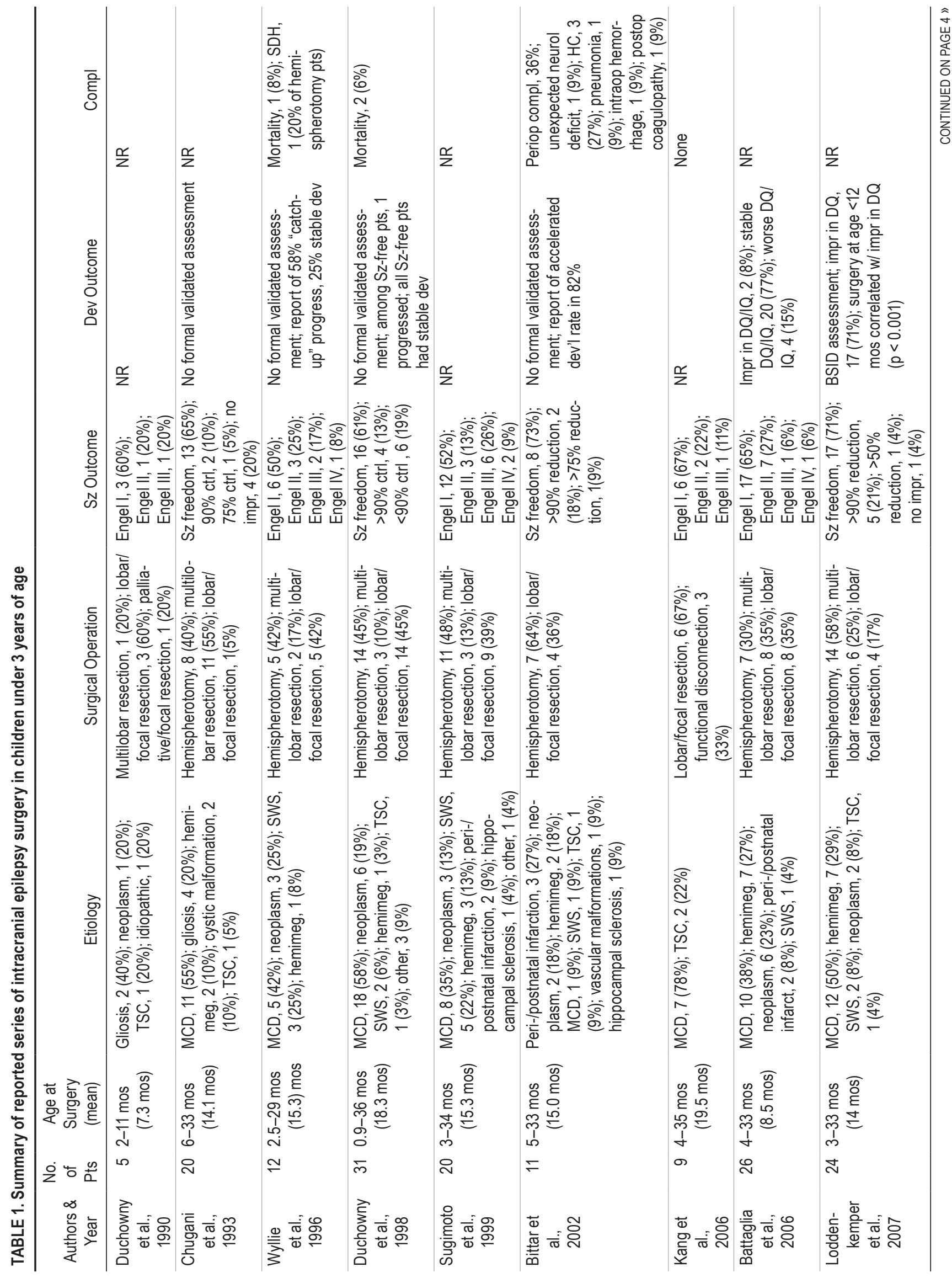




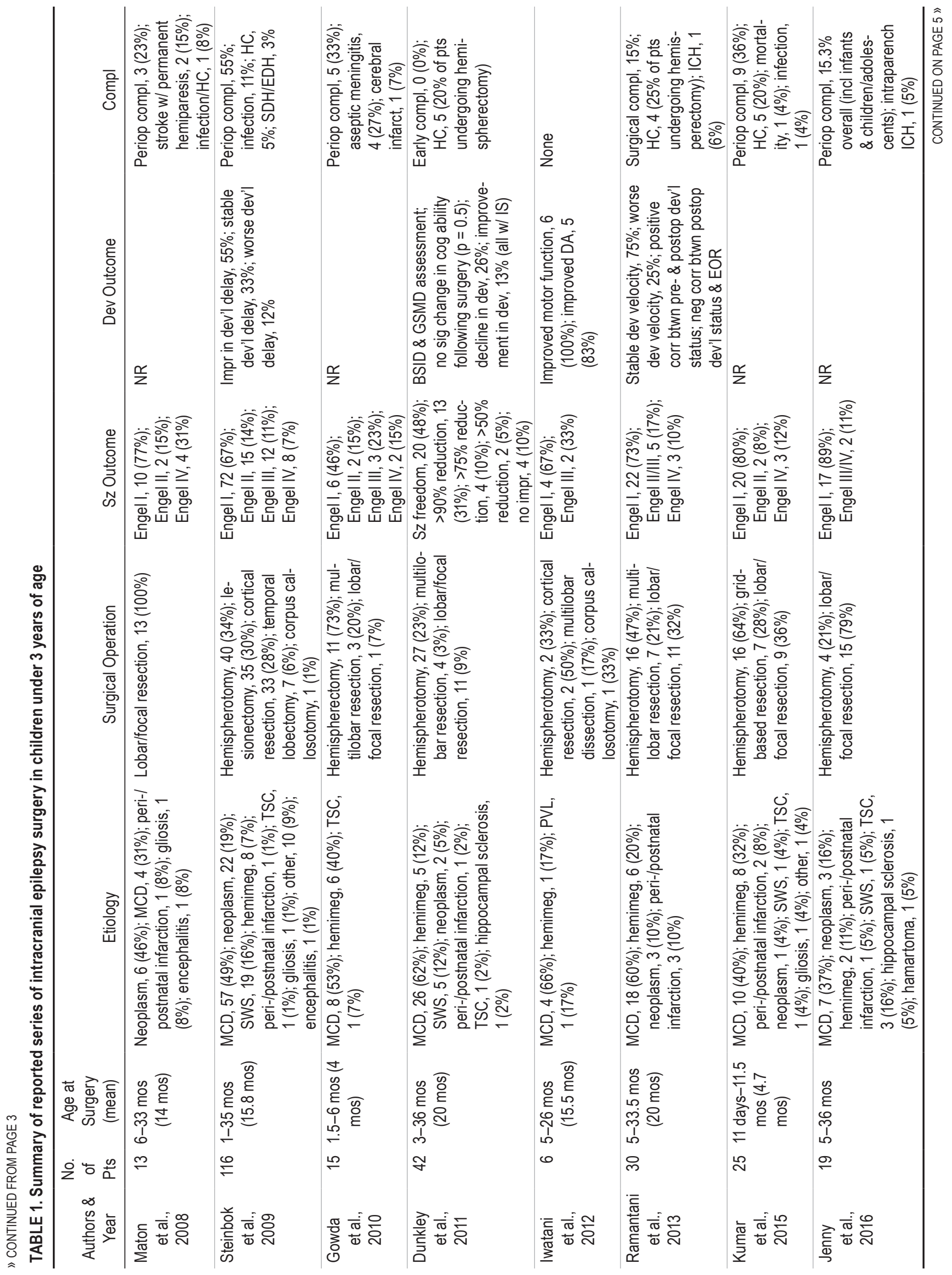




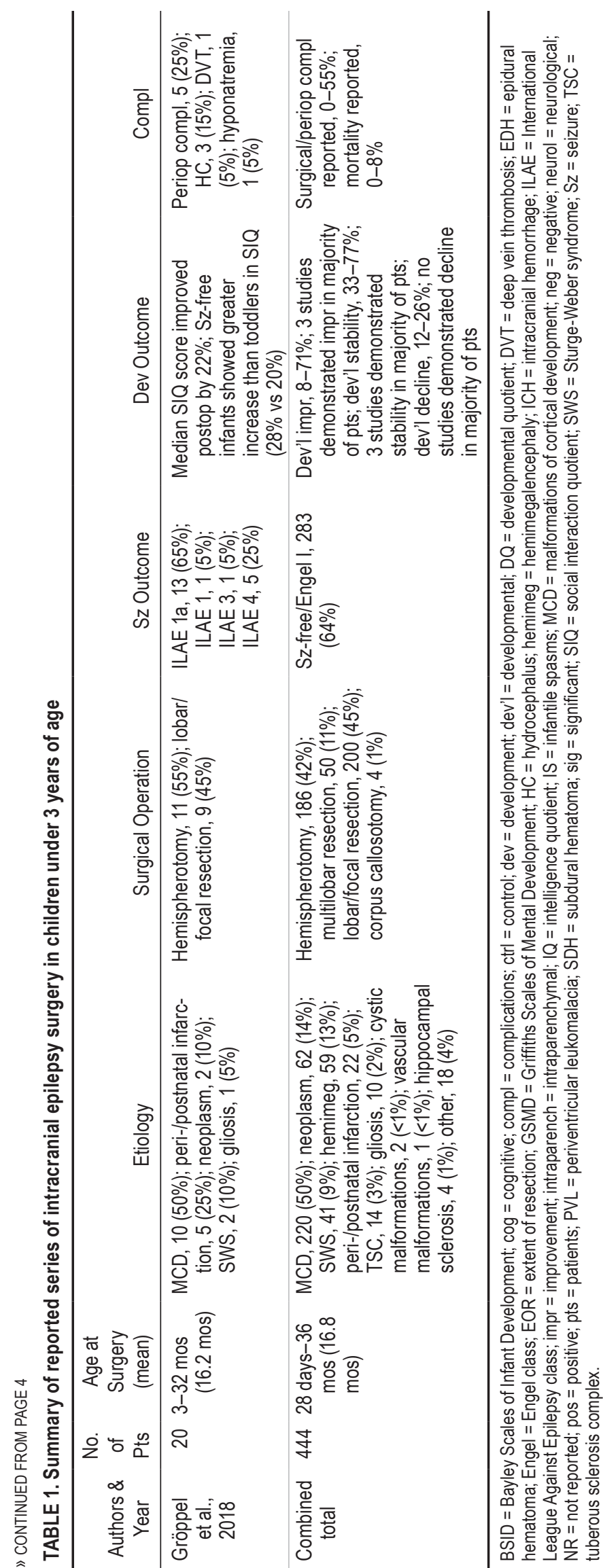

years of age require different surgical approaches. In this systematic review, approximately $90 \%$ of surgeries involved extratemporal resections, multilobar resections, or hemispherectomies/hemispherotomies. In contrast, temporal lobe and anteromesial temporal resections comprise more than $50 \%$ of epilepsy surgeries performed in older children and adults..$^{34,62}$ Anatomical hemispherectomy and functional hemispherotomy accounted for $42 \%$ of epilepsy surgeries performed in infants and toddlers, representing a much higher frequency than similar extensive surgery in older patients.

Larger areas of resection or disconnection improve seizure outcomes in this young age group. Reported seizurefreedom rates for infants and toddlers undergoing surgical treatment of DRE vary between $45 \%$ and $90 \%$ overall and $65 \%$ and $85 \%$ specifically for young patients undergoing hemispherotomy or hemispherectomy. $12,13,15,20-22,30,31$, $35,40,42,45,50-53,58,59,69,70,73$ Sugimoto et al. demonstrated more favorable postsurgical outcomes in young patients with SWS and low-grade gliomas as compared to MCD, while reporting superior seizure outcomes for patients undergoing hemispherectomy ( $82 \%$ Engel class I or II) as opposed to focal cortical resection (50\% Engel class I or II). ${ }^{70} \mathrm{In}$ another retrospective series, young patients with DRE due to SWS who underwent complete cortical resection or hemispherectomy/hemispherotomy had better rates of seizure freedom (94\%) than those who underwent subtotal resection (30\%). ${ }^{13}$ Hemimegalencephaly and cortical dysplasia typically confer worse prognoses regarding seizure outcomes without surgery. ${ }^{35,50,69}$ Despite these challenges, Honda et al. reported an acceptable seizure-freedom rate (66.7\%) in infants with hemimegalencephaly following early hemispherotomy, with the patients who did not gain seizure freedom achieving significantly reduced seizure frequency and improved quality of life. ${ }^{35}$ VNS insertion has provided for seizure reduction in 33\%-66\% of children less than 3 years of age, with a $0 \%-13 \%$ rate of surgical complications (device infection), although data are limited due to lower utilization rates in very young children (Table 2). ${ }^{27,75}$

In open intracranial surgery, targeted plans may incorporate preoperative studies and/or invasive monitoring to better define extents of resection. Chugani et al. demonstrated the utility of positron emission tomography (PET) in the surgical treatment of young patients (age range 5 months to 3 years) with DRE and infantile spasms. ${ }^{16}$ The authors reported consistent findings of abnormal cerebral glucose metabolism (typically hypo-metabolism, 18/23) in all patients studied, with good correlation to interictal and ictal electrographic abnormalities during scalp long-term monitoring electroencephalography (LTME). Given these concordant phase I monitoring findings, the surgical team performed single-stage operations involving cortical resection $(15 / 23)$ or hemispherectomy $(8 / 23)$, without the need for invasive testing and with favorable seizure outcomes (65\% Engel class I; $78 \%$ with $\geq 90 \%$ seizure reduction or control). ${ }^{15}$ Other published data highlight limitations of noninvasive testing. Snead et al. demonstrated that only 2 of $13(15 \%)$ children with DRE exhibited concordant findings between fluorodeoxyglucose (FDG)-PET and chronic invasive monitoring. ${ }^{67}$ In young children, given the higher 
TABLE 2. Summary of reported series on VNS insertion in children under 3 years of age

\begin{tabular}{|c|c|c|c|c|c|c|}
\hline $\begin{array}{c}\text { Authors \& } \\
\text { Year }\end{array}$ & $\begin{array}{l}\text { No. of } \\
\text { Pts }\end{array}$ & $\begin{array}{l}\text { Age Range, } \\
\text { mos (mean) }\end{array}$ & Etiology & Sz Outcome & $\begin{array}{c}\text { Dev } \\
\text { Outcome }\end{array}$ & Complications \\
\hline $\begin{array}{r}\text { Zamponi et } \\
\text { al., } 2008\end{array}$ & 6 & $6-31(17.8)$ & $\begin{array}{l}\text { Malignant migrating partial epilepsy of infancy, } 3(50 \%) \text {; } \\
\text { peri-/postnatal infarction, } 1(17 \%) \text {; hemimeg, } 1(17 \%) \text {; } \\
\text { TSC, } 1(17 \%)\end{array}$ & $\begin{array}{l}\text { Sz freedom, } 1(17 \%) \\
\quad 60-90 \% \text { reduction, } 4 \\
\quad(67 \%) ; \text { no impr, } 1(17 \%)\end{array}$ & $\begin{array}{l}\text { No sig } \\
\text { impr }\end{array}$ & None \\
\hline $\begin{array}{l}\text { Fernandez et } \\
\text { al., } 2015\end{array}$ & 15 & $12-35(26)$ & $\begin{array}{l}\text { Aicardi syndrome, } 3(20 \%) \text {; Miller-Dicker syndrome, } 1 \\
\text { (7\%); neuronal migration disorder, } 1 \text { ( } 7 \%) \text {; genetic w/o } \\
\text { brain malformation, } 1(7 \%) \text {; perinatal insult, } 1(7 \%) ; \\
\text { idiopathic, } 3(20 \%)\end{array}$ & $\begin{array}{l}\text { Improved, } 2(14 \%) \\
\text { unchanged, } 8(57 \%) \\
\text { worse, } 4(29 \%)\end{array}$ & NR & $\begin{array}{l}\text { Device infection, } \\
2(13 \%)\end{array}$ \\
\hline
\end{tabular}

prevalence of extratemporal lobe epilepsy (ETLE), FDGPET may fail to recognize congenital structural anomalies like MCD or may inadequately estimate the extent of the epileptogenic zone. ${ }^{67}$

In the context of discordant (or insufficient) phase I monitoring findings, invasive monitoring may determine the epileptogenic zone and identify eloquent cortex. Intracranial electroencephalography (ICEEG) has been performed safely and effectively in young children using intraoperative electrocorticography (ECog) or extraoperative subdural LTME. Sugimoto et al. reported the ability to identify epileptiform discharges during intraoperative ECog from all study patients (23/23) $0-3$ years of age undergoing single-stage surgery for DRE with various etiologies. ${ }^{70}$ In that retrospective series, nearly $80 \%(18 / 23)$ of patients exhibited concordant localization of ictal and interictal abnormalities, while 43\% (10/23) showed concordant localization of intraoperative ECog and preoperative ictal scalp LTME findings. ${ }^{70}$ Duchowny et al. demonstrated the safety and utility of extraoperative subdural LTME with reduced arrays (due to smaller cortical surface areas) in children below 3 years of age. ${ }^{20,21}$ In their retrospective study, the authors described subdural grid insertion in 11 of 31 patients undergoing subsequent phase II monitoring, sensorimotor electrical stimulation mapping (ESM) with direct cortical stimulation, and epileptogenic zone and lesion resection sparing eloquent cortex. ${ }^{20}$ Similarly, Maton et al. described subdural electroencephalography (EEG) electrode insertion in 6 (of 20) young patients with successful localization of the epileptogenic zone (but with less success with ESM). ${ }^{52}$

Newer paradigms offer the potential for less-invasive strategies in the evaluation and treatment of patients with DRE. While applied more frequently in older children and adults, stereotactic electroencephalography (SEEG) with robotic-arm assistance and stereotactic thermal coagulation or laser ablation (SLA) represent minimally invasive options. Cossu et al. performed a retrospective study of a series of young children $(8 / 15<36$ months of age) undergoing SEEG for DRE and reported acceptable mortality $(1 / 15)$, morbidity, and success rates $(80 \%$ Engel class I or II) following resection or radiofrequency thermal coagulation. ${ }^{17}$ Intracerebral electrodes also facilitated ESM. ${ }^{17}$

Despite potentially catastrophic presentations during early life, infants and toddlers with DRE may achieve seizure freedom or substantial seizure reduction following surgery. Retrospective studies have demonstrated greater rates of seizure freedom in children 3 years of age or younger compared to patients $4-17$ years of age. ${ }^{40} \mathrm{Re}-$ ported rates of seizure freedom following epilepsy surgery in infants and toddlers range between $48 \%$ and $89.5 \%$, including $65 \%-85 \%$ following hemispherotomy or hemispherectomy. $6,13,15,35,37,40,50,51,69,70,73$ In general, patients with ETLE exhibit lower rates of seizure freedom (56\%-68\% Engel class I) than patients with TLE undergoing temporal lobectomy $(60 \%-100 \%){ }^{25,40}$ However, infants and toddlers experience a higher prevalence of ETLE and may respond better to resection, with seizure freedom rates as high as $82 \% .{ }^{25,40}$ Earlier surgical intervention increases the likelihood of success, as a meta-analysis has shown that preoperative epilepsy duration of 7 years or less represented a positive predictive factor for Engel class I outcome. ${ }^{25}$ Earlier surgical intervention also may foster improvements in global development and neuro-cognition by decreasing the disruptive effects of refractory seizures and interictal abnormalities. . $^{13,20,25,35,40,51,68,73}$

Young patients with structural hemispheric abnormalities and DRE often exhibit contralateral hemiparesis, other neurological deficits (contralateral hemianopia), cognitive impairments, and developmental delay. ${ }^{30,69}$ Consequently, many epilepsy surgical teams advocate earlier surgical intervention to optimize seizure control, functional retention or recovery, and neuro-cognitive development. . $^{6,13,35,37,51}$ Retrospective studies have reported significant improvements in global, motor, and speech development following functional hemispherotomy or cortical resections in young patients with DRE and preoperative developmental delay. ${ }^{15,37,73}$ For example, earlier intervention represented a positive predictive factor for developmental improvement in young SWS patients with DRE and baseline developmental impairments. ${ }^{13}$ Similarly, shorter preoperative seizure duration was associated with improved postoperative developmental quotients (DQs) within infants undergoing hemispherotomy for hemimegalencephaly. ${ }^{35}$ Additional retrospective studies have demonstrated an inverse relationship between age at the time of surgery and developmental progression, with infants exhibiting greater DQ increases following hemispherectomy or focal resection. ${ }^{51}$ In particular, Loddenkemper et al. showed that infants with epileptic spasms demonstrated the greatest improvement developmentally following surgery (with $71 \%$ of infants overall demonstrating improved DQ), independent of seizure outcome..$^{51}$ Retrospective studies demonstrated a significant direct correlation (or nonsignificant trend) between postoperative seizure freedom and improved development. ${ }^{35,69}$ Even without developmental or cognitive im- 

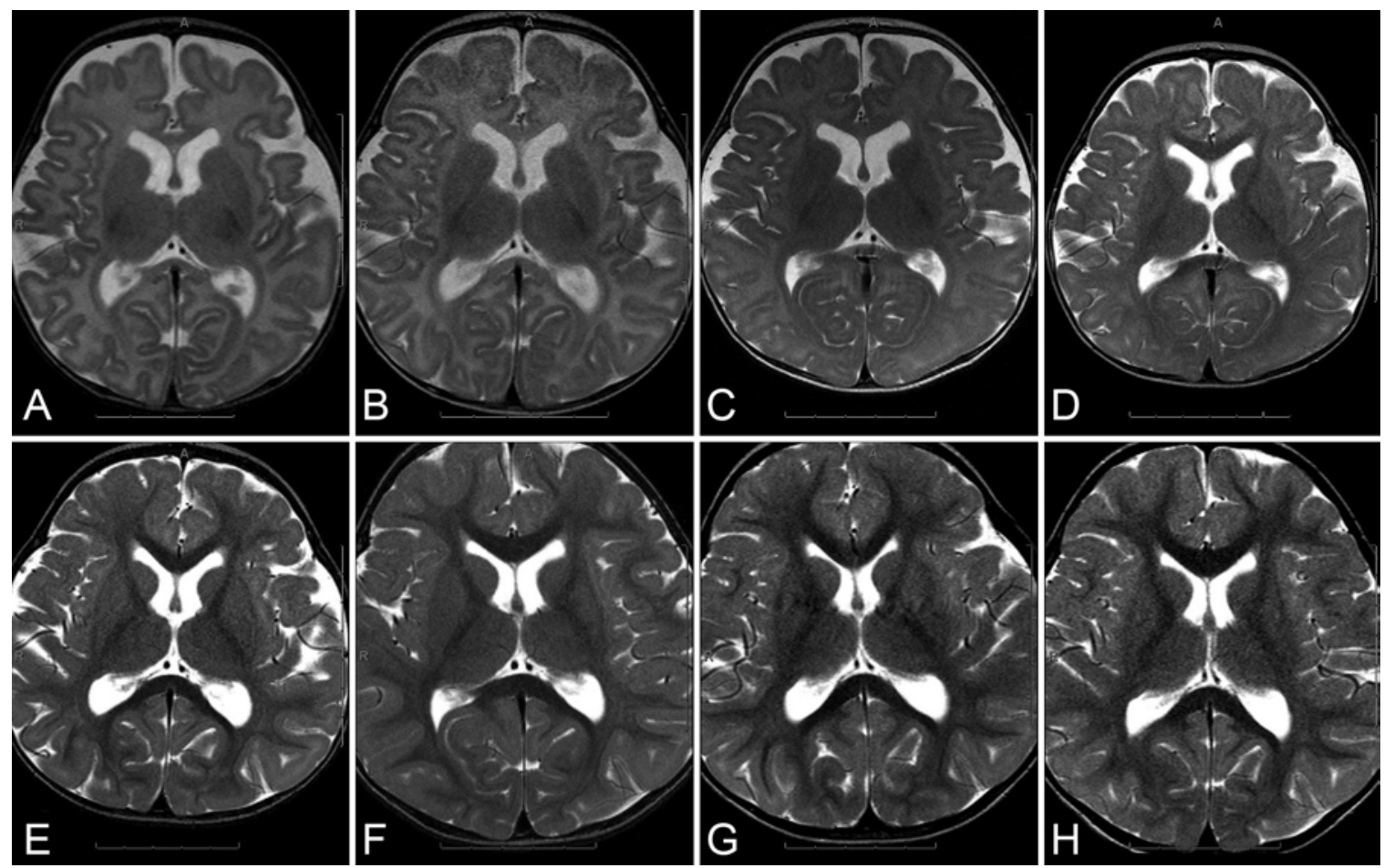

FIG. 2. Radiographic appearance of progressive myelination. Axial T2-weighted brain MRI sequences obtained at 2 (A), 3 (B), 4 (C), $9(\mathbf{D}), 13(\mathbf{E}), 17(\mathbf{F}), 23(\mathbf{G})$, and $28(\mathbf{H})$ months of age demonstrating changes in imaging appearance of cortical and subcortical regions with age. (The images were obtained in a child who underwent repeated screening for atypical teratoid rhabdoid tumor due to a known SMARCB1 genetic mutation risk factor.) Initially the cortex appears hypo-intense compared to white matter, but the white matter becomes hypo-intense as myelination continues. During stages of this process, the distinction between cortical and white matter becomes difficult, thereby complicating evaluation of cortical thickness, white matter arborization, and the contour of the gray-white matter junction.

provement, young children may preserve neuro-cognitive function following epilepsy surgery. ${ }^{6,50}$ Eliminating disruptive influences of epileptiform activity from the aberrant hemisphere may preserve contralateral function and optimize chances for developmental recovery and progression, especially during infancy and critical periods of brain maturation. . $^{15,35,40,50,51,69}$

Resections involving eloquent cortex in younger patients may take advantage of greater neural plasticity that offers better hope for functional recovery. ${ }^{40,50}$ Even without functional improvement, young patients undergoing hemispherotomy may retain the same degree of hemiparesis postoperatively and continue to ambulate. ${ }^{73}$

Enhanced seizure outcomes, improved developmental progress, and greater neural plasticity represent compelling reasons for considering early surgical intervention in infants with DRE. When weighing risks and benefits, catastrophic DRE, with status epilepticus and developmental regression, may prompt earlier surgical intervention during infancy ${ }^{13,35,50,51}$ However, evaluation and treatment of these young children requires special modifications at each step to optimize outcomes and reduce complications.

\section{Special Considerations in Neuroradiology}

Relative immaturity and anticipated development of the infant brain influence radiographic examination of young patients during phase I evaluation. Typically requiring at least 1.5 or $3.0 \mathrm{~T}$ for adequate evaluation of children with DRE, brain MRI allows analysis of gyral and sulcal patterns, cortical thickness, distinction of the gray-white matter junction, cortical signal intensity, subcortical white matter signal intensity, ventricular wall contours, white matter arborization patterns, and regional brain volume. High-resolution MRI may demonstrate subtle findings, including the "transmantle" sign involving white matter signal abnormalities extending toward the ependymal surface of the ventricle. . $, 8,32,41,46,48,49$ While many articles have described imaging findings of MCD, few reports have explored the impact of age and cerebral development on the radiographic depiction of MCD.

For instance, chronological age and brain maturity influence the imaging appearance of FCD. Due to incomplete myelination, FCD may appear relatively indistinct radiographically during earlier ages but may become more apparent as myelination progresses. ${ }^{28,49} \mathrm{On} \mathrm{T} 2$-weighted sequences, myelination causes a hypo-intense (dark) signal within subcortical white matter. The cerebral cortex appears hypo-intense compared to white matter in full-term infants. This relationship reverses as myelination advances, such that cerebral cortex and white matter may demonstrate similar signal intensity during this transition (Fig. 2). Therefore, repeat imaging beyond 24-30 months of age is warranted for infants with DRE and initial unremarkable MRI and may elucidate a previously occult FCD. . $^{5,28,41}$ Given these nuances, radiographic interpretation should 


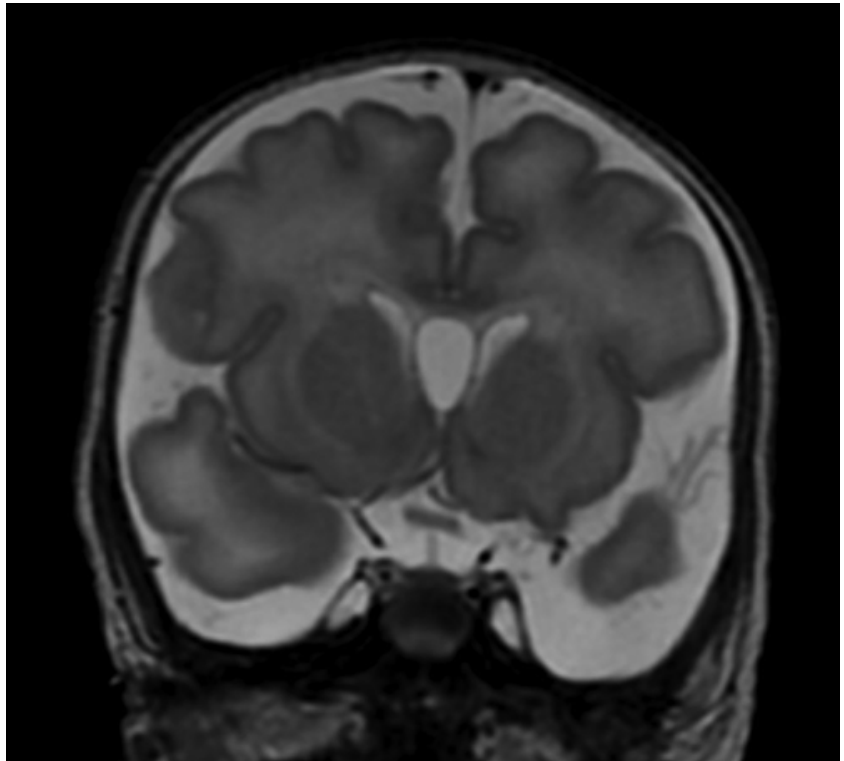

FIG. 3. Simple gyral and sulcal pattern. Coronal T2-weighted brain MR image obtained shortly after birth in a premature infant (31 weeks' gestational age) demonstrating a relatively simplified gyral and sulcal pattern. Primary sulci appear present but relatively shallow, while secondary sulcation appears underdeveloped. Additionally, the sylvian fissures seem relatively wide and the cerebral convexities exhibit smooth contours. While raising concerns in full-term infants, these radiographic findings may remain within the normal range for significant degrees of prematurity.

be performed by an individual with specialized training and/or expertise in pediatric neuroimaging. ${ }^{8,32}$

The radiographic assessment of gyral and sulcal pattern development is also influenced by patient age. For instance, radiographic examination of a premature infant with seizures may suggest the presence of abnormally simplified gyral and sulcal patterns, when this may represent normal gyral development for corrected age (Fig. 3). If structural imaging fails to disclose an obvious lesion, other phase I findings, including PET, may guide focused MRI review. ${ }^{16}$ Age-related nuances of PET include relatively low cerebral glucose metabolism in infants, complicating recognition of subtle hypo-metabolic anomalies, ${ }^{16,67}$ and lenticular nucleus and brainstem hyper-metabolism in infants with infantile spasms. ${ }^{16}$ As an additional functional imaging modality, magnetoencephalography (MEG) may augment phase I evaluation, but with uncertain benefit, given the paucity of published data within this younger age group. In addition to localizing primary motor and somatosensory cortex, MEG may identify interictal dipoles neighboring structural lesions, providing useful information for surgical planning. ${ }^{9}$

\section{Special Considerations in Neurology}

Infants and toddlers undergoing presurgical evaluation require distinct modifications compared to older children or adults. Several factors related to young chronological and developmental age impact preoperative phase I monitoring, including head size, behavioral concerns, incomplete myelination, and dynamic brain maturation. Small cephalic dimensions may necessitate use of an International 10-10 system EEG montage or preclude the use of sphenoidal electrodes..$^{73}$ Behavior, such as irritability, impulsivity, and inability to follow commands, presents logistical challenges, including difficulty maintaining consistent video coverage during LTME and inadequate response testing. ${ }^{74}$ Therefore, young patients benefit from involvement of supporting or ancillary staff (child life, music therapy, etc.).

In addition to difficulties collecting adequate LTME data, seizure classification and EEG interpretation are challenging in younger patients. While frequently helpful in older children and adults, seizure semiology may contribute less information regarding lateralization and localization in infants due to inability to communicate, frequent nonspecific stereotyped body movements, unclear changes in level of consciousness, and/or inconsistent head deviation (ipsilateral or contralateral to hemispheric ictal onset). For example, bilateral or diffuse torso and extremity movements may suggest generalized seizure activity despite the presence of focal EEG changes. ${ }^{19}$ Ictal EEG recordings may also appear more generalized or diffuse, as with epileptic spasms or diffuse tonic seizures, even in the setting of an epileptogenic lesion. Interictal EEG abnormalities may be absent, multifocal, or diffuse (as with hypsarrhythmia). In contrast to older children and adults, infants and toddlers with DRE experience more frequent seizures and are at greater risk for status epilepticus. ${ }^{69}$ Nevertheless, the increased seizure frequency may allow shorter admissions for phase I or phase II monitoring. ${ }^{20}$

Phase II monitoring presents obstacles for safety and data interpretation in younger patients. Disruptive behavior or agitation may result in damage or displacement of indwelling ICEEG electrodes. Despite these risks and challenges, ICEEG-including insertion of subdural grid and strip electrodes and SEEG - has been used safely and effectively in infants and toddlers. ${ }^{18,74}$ Sedating medications (including midazolam) used to decrease these risks may suppress seizure activity, alter ESM or other neurophysiology results, and require prolonged intubation. ${ }^{2}$ Dexmedetomidine and chloral hydrate, however, do not interfere with electrophysiological data and may facilitate safe data collection. ${ }^{26,33}$

Useful ESM has been reported in infants and toddlers, though with lower success rates and requirements for higher current application. ${ }^{10,38,72}$ For instance, adequate primary motor cortex stimulation in young children may require up to $20 \mathrm{~mA}$ of current and longer train durations (25 seconds) during extraoperative ESM (using $50-\mathrm{Hz}$ biphasic pulses of 0.2 -msec duration). ${ }^{14,20}$ Intraoperative ESM also may be limited by age, but has been performed during tumor resection in children as young as 3 years with currents up to $12.5 \mathrm{~mA} .^{65}$ Furthermore, language ESM is less successful in children below the age of 10 years and represents an improbable task in infants and toddlers..$^{52,63}$

Other neurophysiological studies can assist in locating eloquent cortex and critical anatomical landmarks in younger patients. Somatosensory evoked potentials provide more reliable and efficient identification of the central sulcus as compared to ESM in children below 5 years of age. ${ }^{29}$ High gamma electrocorticography (ECog) may 
also assist identification of primary sensorimotor cortex in young children. ${ }^{72}$ Noninvasive adjuncts for ESM include resting-state functional MRI, MEG, and transcranial magnetic stimulation, although data and availability are limited..$^{3,60,72}$

\section{Special Considerations in Neuropsychological Assessment}

Neuropsychological evaluation represents an essential component of the presurgical evaluation for patients with DRE, yet few studies have described formal neurodevelopmental testing in infants and toddlers. ${ }^{39,51,61}$ Standardized evaluation may reveal previously unrecognized developmental and cognitive strengths or weaknesses, foster early developmental and behavioral interventions or postsurgical rehabilitative efforts, and identify family psychosocial needs during the epilepsy surgery process. Given the high rates of distress among parents of young children with medical needs and the potential negative impact of parental distress on child development, addressing psychosocial needs early may contribute substantially to patient outcome. ${ }^{36}$ Younger age of seizure onset and longer preoperative duration of epilepsy represent risk factors for poor neuropsychological function and behavior in young patients, highlighting the importance of proper evaluation before and after epilepsy surgery. $7,22,42,53,66,71$

\section{Special Considerations in Neurosurgery}

Special considerations in the neurosurgical management of young patients with DRE relate to soft tissue handling, positioning, body weight and blood volume, extent of resection, anticipated seizure outcomes, and potential for functional recovery. Care must be taken when positioning young patients in rigid fixation due to their thin, immature calvaria. Some authors recommend less than $20 \mathrm{lbs}$ pressure in patients at the ages of $1-2$ years ${ }^{11}$ to decrease the risks of skull or dural penetration, intracranial hemorrhage, or CSF leakage, while others (including the author) avoid rigid fixation in patients less than 3 years of age. ${ }^{1}$

Compression devices (Raney clips) along scalp edges should be used sparingly to prevent skin necrosis and allow for optimal wound healing. Infants are at high risk of intraoperative hypothermia and subsequent coagulopathy due to poor body temperature regulation. This requires external warming devices (e.g., 3M Bair hugger), prophylactic warming of blood products and fluids, and close attention by the anesthesiology team. Perioperative blood loss represents the leading cause of mortality in infants and toddlers undergoing epilepsy surgery. ${ }^{56,57}$ During the first 12 weeks of life, hemoglobin values decrease to a physiological nadir around $9.0 \mathrm{~g} / \mathrm{dl}$ and may not return to normal until 6 months of age, when the infant's bone marrow becomes the main site of hematopoiesis. ${ }^{4}$ To help determine the necessity and/or timing of transfusion, estimations of total blood volume (TBV) as a function of body weight (stratified by age) have been reported previously: preterm neonates $(100 \mathrm{ml} / \mathrm{kg})$; full-term neonates $(90 \mathrm{ml} / \mathrm{kg})$; infants $\leq 1$ year of age $(80 \mathrm{ml} / \mathrm{kg})$; and patients $1-12$ years of age $(75 \mathrm{ml} / \mathrm{kg}){ }^{68}$ When estimated blood loss (EBL) exceeds $13 \mathrm{ml} / \mathrm{kg}$ in young patients, there is a higher risk of needing a blood transfusion. ${ }^{4}$

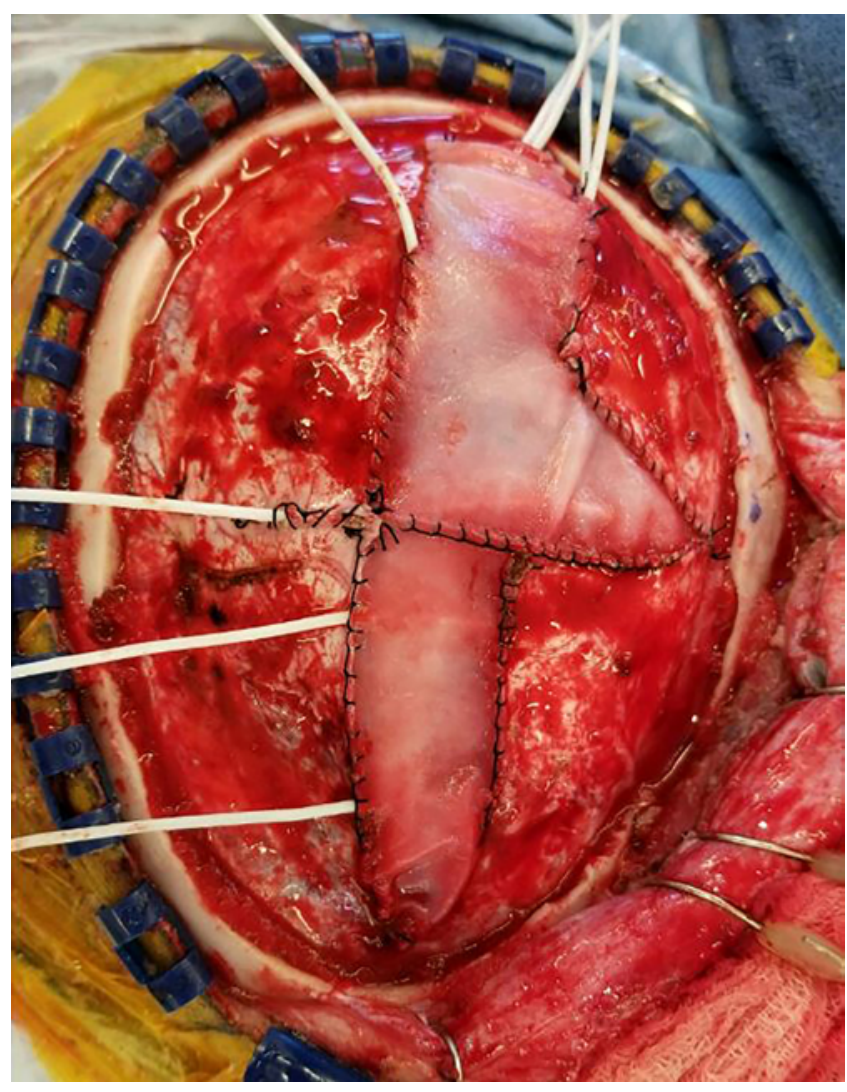

FIG. 4. Expansive duraplasty during insertion of subdural grid and strip electrodes. This intraoperative photograph demonstrates the senior author's (J.P.) incorporation of an expansive duraplasty during the first stage surgery for a 2-year-old boy with TSC and DRE, in preparation for chronic invasive ICEEG long-term monitoring. The expansive duraplasty accommodates the additional volume contributed by subdural grid and strip electrodes and reduces the risks related to cortical compression and mass effect.

Despite close attention to hemostasis and blood transfusions, certain surgical procedures involve anticipated blood loss that exceeds levels that are safe or tolerable for young patients. Functional hemispherotomy, anatomical hemispherectomy, and extensive cortical resections may lead to significant blood loss, especially in infants with hemimegalencephaly or SWS, in whom perioperative transfusions averaged $34 \mathrm{ml} / \mathrm{kg} .{ }^{13,30,35,43,50}$ Voluminous blood transfusions ranging from 320 to $550 \mathrm{ml}$ are reported in young patients (5 years or less) undergoing hemispherotomy, hemispherectomy, or hemidecortication. ${ }^{52}$ In these cases, preplanning staged surgical approaches may reduce surgical and anesthetic risk. The need for transfusion of other factors, including platelets and fresh frozen plasma (FFP), must also be considered. We do not typically use transexamic acid or reconstituted whole blood. ${ }^{11}$

Anesthesia protocols for epilepsy surgery typically account for the performance of motor mapping or ICEEG, and whether elevated intracranial pressure (ICP) may become a concern. Intraoperative postresection ECog helps guide extent of resection in conjunction with the findings of phase I/II monitoring. Special considerations must be given to the risks of elevated ICP with subdural grid insertion in infants and toddlers. Rates of cerebral edema 
in children undergoing subdural electrode insertion may reach as high as $14 \% .{ }^{17}$ At the time of subdural electrode placement, use of an expansive duraplasty may minimize the risk of intracranial hypertension, with a low risk of CSF leakage (Fig. 4).

Typically high seizure frequency and antiseizure medication discontinuation may permit shorter durations of extraoperative ICEEG in younger patients. ${ }^{69}$

Newer diagnostic and treatment paradigms incorporate SEEG with robotic-arm assistance and radiofrequency thermal coagulation or stereotactic laser ablation (SLA) as less-invasive options. Despite the technical challenges of achieving cranial immobilization and satisfying threshold skull thickness ( $\geq 2 \mathrm{~mm}$ ) for peg fixation (to insert the depth electrodes), SEEG and SLA represent potentially useful, less-invasive strategies for evaluating and treating DRE in younger patients. ${ }^{17}$ Published data remain limited for both modalities in infants and toddlers.

\section{Conclusions}

Preoperative evaluation and surgical management of infants and toddlers with DRE offer substantial opportunities for favorable outcomes regarding seizure frequency and neuro-cognitive development. Young chronological and developmental age, physiological immaturity, small body size, and low blood volumes present nuances and unique challenges in the assessment and management of this young population. Epilepsy surgery represents a safe and effective treatment strategy for infants and toddlers with DRE, but requires modifications in evaluation and management from multiple disciplines.

\section{References}

1. Agrawal D, Steinbok P: Simple technique of head fixation for image-guided neurosurgery in infants. Childs Nerv Syst 22:1473-1474, 2006

2. Aksu R, Kumandas S, Akin A, Bicer C, Gümüş H, Güler G, et al: The comparison of the effects of dexmedetomidine and midazolam sedation on electroencephalography in pediatric patients with febrile convulsion. Paediatr Anaesth 21:373378, 2011

3. Alberstone CD, Skirboll SL, Benzel EC, Sanders JA, Hart BL, Baldwin NG, et al: Magnetic source imaging and brain surgery: presurgical and intraoperative planning in 26 patients. J Neurosurg 92:79-90, 2000

4. Arora S, Marwaha N, Dhawan HK, Rao KLN: Dedicated donor unit transfusions reduces donor exposure in pediatric surgery patients. Asian J Transfus Sci 11:124-130, 2017

5. Bartolini L, Whitehead MT, Ho CY, Sepeta LN, Oluigbo CO, Havens K, et al: Temporal lobe epilepsy and focal cortical dysplasia in children: a tip to find the abnormality. Epilepsia 58:113-122, 2017

6. Battaglia D, Chieffo D, Lettori D, Perrino F, Di Rocco C, Guzzetta F: Cognitive assessment in epilepsy surgery of children. Childs Nerv Syst 22:744-759, 2006

7. Battaglia D, Randò T, Deodato F, Bruccini G, Baglio G, Frisone MF, et al: Epileptic disorders with onset in the first year of life: neurological and cognitive outcome. Eur J Paediatr Neurol 3:95-103, 1999

8. Battal B, Ince S, Akgun V, Kocaoglu M, Ozcan E, Tasar M: Malformations of cortical development: 3T magnetic resonance imaging features. World J Radiol 7:329-335, 2015

9. Bennett-Back O, Ochi A, Widjaja E, Nambu S, Kamiya A,
Go C, et al: Magnetoencephalography helps delineate the extent of the epileptogenic zone for surgical planning in children with intractable epilepsy due to porencephalic cyst/ encephalomalacia. J Neurosurg Pediatr 14:271-278, 2014

10. Berger MS, Kincaid J, Ojemann GA, Lettich E: Brain mapping techniques to maximize resection, safety, and seizure control in children with brain tumors. Neurosurgery 25:786-792, 1989

11. Berry C, Sandberg DI, Hoh DJ, Krieger MD, McComb JG: Use of cranial fixation pins in pediatric neurosurgery. Neurosurgery 62:913-919, 2008

12. Bittar RG, Rosenfeld JV, Klug GL, Hopkins IJ, Harvey AS: Resective surgery in infants and young children with intractable epilepsy. J Clin Neurosci 9:142-146, 2002

13. Bourgeois M, Crimmins DW, de Oliveira RS, Arzimanoglou A, Garnett M, Roujeau T, et al: Surgical treatment of epilepsy in Sturge-Weber syndrome in children. J Neurosurg 106 (1 Suppl):20-28, 2007

14. Chitoku S, Otsubo H, Harada Y, Jay V, Rutka JT, Weiss SK, et al: Extraoperative cortical stimulation of motor function in children. Pediatr Neurol 24:344-350, 2001

15. Chugani HT, Shewmon DA, Peacock WJ, Shields WD, Mazziotta JC, Phelps ME: Surgical treatment of intractable neonatal-onset seizures: the role of positron emission tomography. Neurology 38:1178-1188, 1988

16. Chugani HT, Shewmon DA, Shields WD, Sankar R, Comair Y, Vinters HV, et al: Surgery for intractable infantile spasms: neuroimaging perspectives. Epilepsia 34:764-771, 1993

17. Cossu M, Schiariti M, Francione S, Fuschillo D, Gozzo F, Nobili L, et al: Stereoelectroencephalography in the presurgical evaluation of focal epilepsy in infancy and early childhood. J Neurosurg Pediatr 9:290-300, 2012

18. Dorfmüller G, Ferrand-Sorbets S, Fohlen M, Bulteau C, Archambaud F, Delalande O, et al: Outcome of surgery in children with focal cortical dysplasia younger than 5 years explored by stereo-electroencephalography. Childs Nerv Syst 30:1875-1883, 2014

19. Dravet C, Catani C, Bureau M, Roger J: Partial epilepsies in infancy: a study of 40 cases. Epilepsia 30:807-812, 1989

20. Duchowny M, Jayakar P, Resnick T, Harvey AS, Alvarez L, Dean P, et al: Epilepsy surgery in the first three years of life. Epilepsia 39:737-743, 1998

21. Duchowny MS, Resnick TJ, Alvarez LA, Morrison G: Focal resection for malignant partial seizures in infancy. Neurology 40:980-984, 1990

22. Dunkley C, Kung J, Scott RC, Nicolaides P, Neville B, Aylett SE, et al: Epilepsy surgery in children under 3 years. Epilepsy Res 93:96-106, 2011

23. Dwivedi R, Ramanujam B, Chandra PS, Sapra S, Gulati S, Kalaivani M, et al: Surgery for drug-resistant epilepsy in children. N Engl J Med 377:1639-1647, 2017

24. Engel J Jr: Surgery for seizures. N Engl J Med 334:647-652, 1996

25. Englot DJ, Breshears JD, Sun PP, Chang EF, Auguste KI: Seizure outcomes after resective surgery for extra-temporal lobe epilepsy in pediatric patients. J Neurosurg Pediatr 12:126-133, 2013

26. Fernandes ML, Oliveira WM, Santos MdoC, Gomez RS: Sedation for electroencephalography with dexmedetomidine or chloral hydrate: a comparative study on the qualitative and quantitative electroencephalogram pattern. J Neurosurg Anesthesiol 27:21-25, 2015

27. Fernandez L, Gedela S, Tamber M, Sogawa Y: Vagus nerve stimulation in children less than 3 years with medically intractable epilepsy. Epilepsy Res 112:37-42, 2015

28. Gaillard WD, Chiron C, Cross JH, Harvey AS, Kuzniecky R, Hertz-Pannier L, et al: Guidelines for imaging infants and children with recent-onset epilepsy. Epilepsia 50:2147-2153, 2009 
29. Gallentine WB, Mikati MA: Intraoperative electrocorticography and cortical stimulation in children. J Clin Neurophysiol 26:95-108, 2009

30. Gowda S, Salazar F, Bingaman WE, Kotagal P, Lachhwani DL, Gupta A, et al: Surgery for catastrophic epilepsy in infants 6 months of age and younger. J Neurosurg Pediatr 5:603-607, 2010

31. Gröppel G, Dorfer C, Dressler A, Mühlebner A, Porsche B, Czech T, et al: Epilepsy surgery in infants: safety issues and developmental outcome. Wien Klin Wochenschr 130:341348,2018

32. Guerrini R, Dobyns WB: Malformations of cortical development: clinical features and genetic causes. Lancet Neurol 13:710-726, 2014

33. Gumus H, Bayram AK, Poyrazoglu HG, Canpolat DG, Per $\mathrm{H}$, Canpolat M, et al: Comparison of effects of different dexmedetomidine and chloral hydrate doses used in sedation on electroencephalography in pediatric patients. J Child Neurol 30:983-988, 2015

34. Harvey AS, Cross JH, Shinnar S, Mathern GW: Defining the spectrum of international practice in pediatric epilepsy surgery patients. Epilepsia 49:146-155, 2008 (Erratum in Epilepsia 54:1140, 2013)

35. Honda R, Kaido T, Sugai K, Takahashi A, Kaneko Y, Nakagwa E, et al: Long-term developmental outcome after early hemispherotomy for hemimegalencephaly in infants with epileptic encephalopathy. Epilepsy Behav 29:30-35, 2013

36. Hynan MT, Mounts KO, Vanderbilt DL: Screening parents of high-risk infants for emotional distress: rationale and recommendations. J Perinatol 33:748-753, 2013

37. Iwatani Y, Kagitani-Shimono K, Tominaga K, Okinaga T, Mohri I, Kishima H, et al: Long-term developmental outcome in patients with West syndrome after epilepsy surgery. Brain Dev 34:731-738, 2012

38. Jayakar P, Alvarez LA, Duchowny MS, Resnick TJ: A safe and effective paradigm to functionally map the cortex in childhood. J Clin Neurophysiol 9:288-293, 1992

39. Jayakar P, Gaillard WD, Tripathi M, Libenson MH, Mathern GW, Cross JH: Diagnostic test utilization in evaluation for resective epilepsy surgery in children. Epilepsia 55:507-518, 2014

40. Jenny B, Smoll N, El Hassani Y, Momjian S, Pollo C, Korff $\mathrm{CM}$, et al: Pediatric epilepsy surgery: could age be a predictor of outcomes? J Neurosurg Pediatr 18:235-241, 2016

41. Jeon TY, Kim JH, Lee J, Yoo SY, Hwang SM, Lee M: Value of repeat brain MRI in children with focal epilepsy and negative findings on initial MRI. Korean J Radiol 18:729-738, 2017

42. Jonas R, Asarnow RF, LoPresti C, Yudovin S, Koh S, Wu JY, et al: Surgery for symptomatic infant-onset epileptic encephalopathy with and without infantile spasms. Neurology 64:746-750, 2005

43. Jonas R, Nguyen S, Hu B, Asarnow RF, LoPresti C, Curtiss $\mathrm{S}$, et al: Cerebral hemispherectomy: hospital course, seizure, developmental, language, and motor outcomes. Neurology 62:1712-1721, 2004

44. Kang HC, Hwang YS, Park JC, Cho WH, Kim SH, Kim HD, et al: Clinical and electroencephalographic features of infantile spasms associated with malformations of cortical development. Pediatr Neurosurg 42:20-27, 2006

45. Kumar RM, Koh S, Knupp K, Handler MH, O’Neill BR: Surgery for infants with catastrophic epilepsy: an analysis of complications and efficacy. Childs Nerv Syst 31:1479-1491, 2015

46. Kuzniecky R: Epilepsy and malformations of cortical development: new developments. Curr Opin Neurol 28:151-157, 2015

47. Kwan P, Arzimanoglou A, Berg AT, Brodie MJ, Allen Hauser W, Mathern G, et al: Definition of drug resistant epilepsy: consensus proposal by the ad hoc Task Force of the ILAE Commission on Therapeutic Strategies. Epilepsia 51:10691077,2010

48. Leach JL, Greiner HM, Miles L, Mangano FT: Imaging spectrum of cortical dysplasia in children. Semin Roentgenol 49:99-111, 2014

49. Lerman-Sagie T, Leibovitz Z: Malformations of cortical development: from postnatal to fetal imaging. Can J Neurol Sci 43:611-618, 2016

50. Lettori D, Battaglia D, Sacco A, Veredice C, Chieffo D, Massimi L, et al: Early hemispherectomy in catastrophic epilepsy: a neuro-cognitive and epileptic long-term follow-up. Seizure 17:49-63, 2008

51. Loddenkemper T, Holland KD, Stanford LD, Kotagal P, Bingaman W, Wyllie E: Developmental outcome after epilepsy surgery in infancy. Pediatrics 119:930-935, 2007

52. Maton B, Jayakar P, Resnick T, Morrison G, Ragheb J, Duchowny M: Surgery for medically intractable temporal lobe epilepsy during early life. Epilepsia 49:80-87, 2008

53. Mikati MA, Ataya N, Ferzli J, Kurdi R, El-Banna D, Rahi A, et al: Quality of life after surgery for intractable partial epilepsy in children: a cohort study with controls. Epilepsy Res 90:207-213, 2010

54. Nolan MA, Redoblado MA, Lah S, Sabaz M, Lawson JA, Cunningham AM, et al: Intelligence in childhood epilepsy syndromes. Epilepsy Res 53:139-150, 2003

55. Otsuki T, Kim HD, Luan G, Inoue Y, Baba H, Oguni H, et al: Surgical versus medical treatment for children with epileptic encephalopathy in infancy and early childhood: Results of an international multicenter cohort study in Far-East Asia (the FACE study). Brain Dev 38:449-460, 2016

56. Peacock WJ, Wehby-Grant MC, Shields WD, Shewmon DA, Chugani HT, Sankar R, et al: Hemispherectomy for intractable seizures in children: a report of 58 cases. Childs Nerv Syst 12:376-384, 1996

57. Pietrini D, Zanghi F, Pusateri A, Tosi F, Pulitanò S, Piastra $\mathrm{M}$ : Anesthesiological and intensive care considerations in children undergoing extensive cerebral excision procedure for congenital epileptogenic lesions. Childs Nerv Syst 22:844-851, 2006

58. Ramantani G, Kadish NE, Strobl K, Brandt A, Stathi A, Mayer H, et al: Seizure and cognitive outcomes of epilepsy surgery in infancy and early childhood. Eur J Paediatr Neurol 17:498-506, 2013

59. Reinholdson J, Olsson I, Edelvik A, Hallböök T, Lundgren J, Rydenhag B, et al: Long-term follow-up after epilepsy surgery in infancy and early childhood-a prospective population based observational study. Seizure 30:83-89, 2015

60. Roland JL, Griffin N, Hacker CD, Vellimana AK, Akbari SH, Shimony JS, et al: Resting-state functional magnetic resonance imaging for surgical planning in pediatric patients: a preliminary experience. J Neurosurg Pediatr 20:583-590, 2017

61. Roulet-Perez E, Davidoff V, Mayor-Dubois C, Maeder-Ingvar M, Seeck M, Ruffieux C, et al: Impact of severe epilepsy on development: recovery potential after successful early epilepsy surgery. Epilepsia 51:1266-1276, 2010

62. Saneto RP, Wyllie E: Epilepsy surgery in infancy. Semin Pediatr Neurol 7:187-193, 2000

63. Schevon CA, Carlson C, Zaroff CM, Weiner HJ, Doyle WK, Miles D, et al: Pediatric language mapping: sensitivity of neurostimulation and Wada testing in epilepsy surgery. Epilepsia 48:539-545, 2007

64. Siegel AM, Jobst BC, Thadani VM, Rhodes CH, Lewis PJ, Roberts DW, et al: Medically intractable, localization-related epilepsy with normal MRI: presurgical evaluation and surgical outcome in 43 patients. Epilepsia 42:883-888, 2001

65. Signorelli F, Guyotat J, Mottolese C, Schneider F, D'Acunzi $\mathrm{G}$, Isnard J: Intraoperative electrical stimulation mapping as 
an aid for surgery of intracranial lesions involving motor areas in children. Childs Nerv Syst 20:420-426, 2004

66. Smith ML, Elliott IM, Lach L: Cognitive skills in children with intractable epilepsy: comparison of surgical and nonsurgical candidates. Epilepsia 43:631-637, 2002

67. Snead OC III, Chen LS, Mitchell WG, Kongelbeck SR, Raffel C, Gilles FH, et al: Usefulness of [18F]fluorodeoxyglucose positron emission tomography in pediatric epilepsy surgery. Pediatr Neurol 14:98-107, 1996

68. Soriano SG, Rockoff MA: Pediatric neuroanesthesia, in Albright AL, Pollack IF, Adelson PD (ed): Principles and Practice of Pediatric Neurosurgery, ed 3. New York: Thieme, 2015, Vol 1, pp 1076-1089

69. Steinbok P, Gan PY, Connolly MB, Carmant L, Barry Sinclair D, Rutka J, et al: Epilepsy surgery in the first 3 years of life: a Canadian survey. Epilepsia 50:1442-1449, 2009

70. Sugimoto T, Otsubo H, Hwang PA, Hoffman HJ, Jay V, Snead OC III: Outcome of epilepsy surgery in the first three years of life. Epilepsia 40:560-565, 1999

71. Vasconcellos E, Wyllie E, Sullivan S, Stanford L, Bulacio J, Kotagal P, et al: Mental retardation in pediatric candidates for epilepsy surgery: the role of early seizure onset. Epilepsia 42:268-274, 2001

72. Wray CD, Blakely TM, Poliachik SL, Poliakov A, McDaniel SS, Novotny EJ, et al: Multimodality localization of the sensorimotor cortex in pediatric patients undergoing epilepsy surgery. J Neurosurg Pediatr 10:1-6, 2012

73. Wyllie E, Comair YG, Kotagal P, Raja S, Ruggieri P: Epilepsy surgery in infants. Epilepsia 37:625-637, 1996

74. Wyllie E, Lüders H, Morris HH III, Lesser RP, Dinner DS, Rothner AD, et al: Subdural electrodes in the evaluation for epilepsy surgery in children and adults. Neuropediatrics 19:80-86, 1988

75. Zamponi N, Rychlicki F, Corpaci L, Cesaroni E, Trignani R: Vagus nerve stimulation (VNS) is effective in treating catastrophic 1 epilepsy in very young children. Neurosurg Rev 31:291-297, 2008

\section{Disclosures}

The authors report no conflict of interest concerning the materials or methods used in this study or the findings specified in this paper.

\section{Author Contributions}

Conception and design: Pindrik, Gedela, Ostendorf. Acquisition of data: Pindrik, Hoang, Halverson. Analysis and interpretation of data: Pindrik, Hoang, Smith, Halverson, Ostendorf. Drafting the article: Pindrik, Hoang, Smith, Halverson, Wojnaroski, McNally, Gedela. Critically revising the article: Pindrik, Hoang, Halverson, Wojnaroski, McNally, Ostendorf. Reviewed submitted version of manuscript: all authors. Approved the final version of the manuscript on behalf of all authors: Pindrik. Study supervision: Pindrik, Ostendorf.

\section{Correspondence}

Jonathan Pindrik: Nationwide Children's Hospital and The Ohio State University College of Medicine, Columbus, $\mathrm{OH}$. jonathan. pindrik@nationwidechildrens.org. 